\title{
Postmenopausal hormone therapy: less favourable risk- benefit ratios in healthy Dutch women
}

\author{
C. J. MOERMAN ${ }^{1}$, B. A. VAN HOUT ${ }^{2}$, L. BONNEUX ${ }^{3}$ \& J. C. M. WITTEMAN ${ }^{4}$ \\ From the ${ }^{1}$ Department of Gender and Health, Academic Medical Center, University of Amsterdam, Amsterdam; and the ${ }^{2}$ Institute of Medical Technology \\ Assessment, ${ }^{3}$ Department of Public Health and ${ }^{4}$ Department of Epidemiology E Biostatistics, Erasmus University Medical School, Rotterdam, the \\ Netherlands
}

\begin{abstract}
Moerman CJ, van Hout BA, Bonneux L, Witteman JCM (University of Amsterdam, Amsterdam, and Erasmus University Medical School, Rotterdam, the Netherlands). Postmenopausal hormone therapy: less favourable risk-benefit ratios in healthy Dutch women. J Intern Med 2000; 248: 143150.
\end{abstract}

Objectives. To estimate the health effects of postmenopausal hormone therapy used for 10 or 20 years in a population of intermediate cardiovascular risk.

Design. Using existing estimates of the effect of hormone therapy on rates of myocardial infarction, hip fracture and breast cancer, a proportional multistage life table was generated to calculate the effects of use for 10 and 20 years in a synthetic cohort of Dutch women aged 55 with an average and a highrisk profile for cardiovascular disease.

Results. A woman of the general population who starts hormone therapy at age 55 for 10 years can prolong her life by 1 month and may postpone the occurrence of first incidence of one of the diseases under consideration by 2.4 months. One excess breast cancer case is likely to occur per 5-6 averted cases of first myocardial infarction or hip fracture. If she prolongs her use to 20 years, the gain of life expectancy and disease-free life expectancy is doubled. The risk-benefit ratio worsens to one extra breast cancer per 3-4 averted cases of the preventable diseases. For a woman with a high-risk profile, the gains in health are about twice as high as for her counterpart in the general population, and her riskbenefit ratio is also more favourable. Yet, the riskbenefit ratio still worsens for 20 as compared with 10 years of use.

Conclusions. Women from the general population in the Netherlands and similar populations can achieve only a modest gain in life expectancy by using hormones during 10 or 20 years following menopause. This is a consequence of the low incidence of myocardial infarction and hip fracture and the relatively high incidence of breast cancer before the age of 75 . Women at increased cardiovascular risk can benefit more from hormone therapy. But even amongst these women, the risk of breast cancer incurred with long-term use offsets much of the benefit that could accrue from changing the risk of heart disease and hip fracture.

Keywords: breast neoplasms, coronary heart disease, hip fractures, hormone replacement therapy, middle age, models: theoretical.

\section{Introduction}

Long-term use of postmenopausal hormone therapy is advocated as a preventive measure against various health problems in ageing women. Amongst hormone therapy's most recognized potential benefits are a decrease in the risk of osteoporotic fractures and cardiovascular disease, whilst its most serious potential hazard is an increase in the risk of breast cancer [1,2]. The good prospects of use are mainly based on results of lifelong use amongst American women who run a relatively high risk of cardiovascular disease [3].

Considering its commonness and its deadliness, the frequency of cardiovascular disease is of overriding importance in the balance between benefits 
and hazards. Shortly after menopause, the frequency of cardiovascular disease is still low. Because the frequencies of the disorders involved in the riskbenefit balance vary with age and the hormonerelated effects may vary with the length of period of use, starting age and duration of use become key factors in determining the balance. These factors even grow in significance, because in our view adherence to a lifelong regimen on a large scale is not a realistic assumption. Furthermore, populations and countries differ in their risk of cardiovascular disease. Therefore, a beneficial outcome of hormone treatment in one country does not necessarily imply a similar outcome in other countries.

The main rationale behind the choice of hormones as a preventive measure is their assumed potential to reduce cardiovascular disease, which is based on results from observational studies. The recently reported results of a clinical trial amongst women with documented coronary heart disease has cast doubt on this assumption: there was no hormone-related reduction in cardiovascular events, mainly as a result of a high number of events in the treatment arm in the first year [4]. In the present study, we focus on women of the general population. It is not clear whether women without manifest heart disease will be affected by the use of a hormonal regimen in a similar way. Besides, the results of the trial do not exclude an anti-atherogenic effect of hormones in the longer run. Therefore, we think it is most valid to use the estimates of hormonal effects from observational studies for a risk-benefit analysis in women of the general population.

To date, several computer simulations have attempted to weigh the risks and benefits of longterm hormone replacement therapy [1, 5-8]. All but one [6] refer to white American women. Each of the simulations provides insufficient information to form a well-founded opinion on the health gain attainable for women when the use of hormones is continued for a shorter period than whole of life. Either the simulation studies have reported on health gains for lifelong use and expressed the outcomes in terms of mortality but not morbidity, which provides limited insight into the risk-benefit balance [1,7], or the studies have paid attention to shorter than lifelong use and have reported in more detail on the riskbenefit balance, but have not provided outcomes for women with different cardiovascular risk profiles
$[5,6]$. The most recently published study, aimed at helping women and their physicians to choose the most beneficial therapy, combined all relevant aspects of use in a simulation model [8]. Calculations were made for various durations of use as well as for users with various risk profiles, and outcomes on morbidity and mortality were reported. However, the weighing of benefits against risks was carried out for lifelong use and its effect on mortality only. Results of this weighing process were further used as a basis for the framing of a decision scheme.

We estimated the effect of hormone use for a period of moderate duration on prolongation of life through its effect on myocardial infarction, hip fracture and breast cancer amongst a synthetic cohort of Dutch women aged 55. We computed the effect for women with an average and with a highrisk profile for cardiovascular disease. In addition, we computed hormone-related risk-benefit ratios for the three diseases.

\section{Methods}

The model

Our simulation used a proportional multistage life table which starts the calculations from disease prevalences. It is specially designed to cope with a large number of diseases simultaneously, whilst allowing for co-morbidity [9]. Disease prevalences were calculated from entered data on age-specific incidence and excess mortality for heart attack, hip fracture and breast cancer and on the risk of death from other causes. The model starts at age 55 for all women free from the three diseases under consideration. For each life-year thereafter, the probability of a woman developing one of the diseases of interest is calculated, or, in the case of a woman who has become diseased, the probability of her dying from it and the probability of her dying from other causes. The effect of hormone use on morbidity and mortality is modelled by changing the probabilities to obtain one of the diseases under consideration. Once a woman has become diseased, she is assumed to have stopped using hormones. Her subsequent survival is not affected by hormone use.

Figures on breast cancer were derived from the Comprehensive National Cancer Registry [10] and the Cancer Registry in the south-eastern Nether- 
lands [11]. Hip fracture figures came from a nationwide hospital discharge registry and individual studies on the survival of hip fracture patients [12], and the risk of death from other causes came from a national registry of causes of death [13]. Our measure of heart attack incidence refers to clinically manifest events, i.e. fatal events occurring inside or outside the hospital and non-fatal events resulting in hospital admission. Incidence and excess mortality were derived from mortality statistics and hospital discharge data using estimates of fatality rates and risks of recurrent infarction from literature. Estimated incidences were validated against observational data from the Rotterdam Study [14].

All incidences refer to 1992/1993 figures, with the exception of breast cancer incidence which refers to 1989 figures corrected for contralateral tumours. This was done because in 1990 a nationwide screening programme was implemented. The use of hormones by Dutch women is limited after menopause. An estimated $12 \%$ of the women in the age range 45-60 years is taking hormone replacement therapy, mainly for symptomatic reasons and usually for a short period of time [15]. We therefore assumed that the data sources referred to non-using women.

We defined a group at high risk of myocardial infarction using data from a population-based study, the Rotterdam Study [16]. The criteria were being diabetic or the presence of at least two of the following risk factors: cigarette smoking, hypertension or hypercholesterolaemia. About $14 \%$ of the women between the age of 55 and 64 met the criteria of a high-risk profile (see Table 1). These women were also more frequently obese and had a $20 \%$ greater chance of dying from non-cardiovascular disease up to the age of 80 than the entire group of women in the cohort (unpublished data). We assumed the high-risk women to have a 100 (from age 70 onwards) to $150 \%$ (aged between 55 and 69) higher risk of myocardial infarction [17], a $5 \%$ higher risk of breast cancer because of their obesity [2] and a 20\% higher risk of overall death.

\section{Hormonal effects}

In our model, postmenopausal hormone use affects the occurrence of first events. Following Grady et al.'s [1] assumptions, we assumed that use of hormone therapy - oestrogens alone or in combina-
Table 1 Characteristics of all women aged 55-64 in the Rotterdam Study and of a subgroup of women with a high-risk profile for cardiovascular disease

\begin{tabular}{|c|c|c|}
\hline & $\begin{array}{l}\text { All women } \\
(n=1381)\end{array}$ & $\begin{array}{l}\text { High-risk women }{ }^{\text {a }} \\
(n=196)\end{array}$ \\
\hline Diabetes mellitus (\%) & 5 & 33 \\
\hline \multicolumn{3}{|l|}{ Cigarette smoking (\%) } \\
\hline Current & 26 & 67 \\
\hline Past & 32 & 15 \\
\hline Hypertension $^{\mathrm{b}}(\%)$ & 24 & 73 \\
\hline Hypercholesterolaemia $^{c}(\%)$ & 15 & 49 \\
\hline \multicolumn{3}{|l|}{ Quetelet index $\left(\mathrm{kg} \mathrm{m}^{-2}\right)$} \\
\hline$<25$ & 44 & 34 \\
\hline$\geq 25$ to $<27$ & 21 & 20 \\
\hline$\geq 27$ & 35 & 46 \\
\hline
\end{tabular}

${ }^{\mathrm{a}}$ Diabetic women or women with the presence of at least two of the following risk factors: cigarette smoking, hypertension or hypercholesterolaemia.

${ }^{\mathbf{b}}$ Systolic blood pressure $\geq 160 \mathrm{mmHg}$ and/or diastolic blood pressure $\geq 95 \mathrm{mmHg}$ or antihypertensive medication.

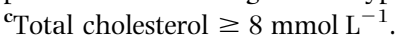

tion with progestins - reduced the risk of myocardial infarction by $36 \%$ and hip fracture by $25 \%$. The protective effects against heart attack and hip fractures were assumed to take effect immediately after the start of use. The risk of breast cancer was assumed to increase only after 5 years of use and then in a two-step fashion (relative risk: $6-10$ years, 1.2 ; > 10 years, 1.35), based on the results of a meta-analysis on the relation between hormone use and breast cancer [2]. The effects of the use were assumed to cease immediately after discontinuation.

The hormone-related relative risk reduction and elevation in the high-risk group were assumed to be similar to those in the population at large except for the breast cancer risk. Since the latter risk is likely to depend on the degree of obesity [2], we assumed a slightly smaller effect in high-risk women (relative risk: $6-10$ years, $1.15 ;>10$ years, 1.3 ).

\section{Outcome measures and analysis}

Outcomes were measured in four ways: the absolute changes in life expectancy and in the time period free from heart attack, hip fracture and breast cancer after the age of 55 (disease-free life expectancy); the number of women needing to undergo treatment in order to prevent one woman from developing a first heart attack or hip fracture (number-needed-to-treat); and the risk-benefit ratio 
reflecting the absolute number of prevented cases of first heart attack or hip fracture in relation to the absolute excess number of cases of breast cancer. In accordance with life expectancy, which is determined by the probability of dying per year of life, the disease-free life expectancy is determined by the probability of getting one of the diseases under consideration or of dying from other causes per year of life.

Among the main problems in establishing the size of a hormone effect on the reduction of coronary heart disease (CHD) are the various sources of bias in observational studies which can considerably overrate the benefit of hormone use [18]. We therefore made additional calculations for a $20 \%$ instead of a $36 \%$ reduction in risk of myocardial infarction. We further performed a sensitivity analysis assuming a $20 \%$ higher or $20 \%$ lower incidence of heart attack, hip fractures and breast cancer.

We report on women of the general population and women at high risk for myocardial infarction owing to their risk profile for both 10 and 20 consecutive years of use.

\section{Results}

The baseline life expectancy of a 55-year-old Dutch woman not undergoing hormone therapy is another 27.2 years, of which she will have 23.7 years free from heart attack, hip fracture or breast cancer. Breast cancer occurs at a much younger age than heart attack or hip fracture; the latter two conditions become a major health problem after the age of 80 (Fig. 1). The absolute risk of a 55 -year-old Dutch woman of a first heart attack within 10 years is $2.8 \%$, that of a first hip fracture is $0.8 \%$, and that of a clinical (not screening-detected) breast cancer diagnosis is $2.1 \%$. The figures for the risks within 20 years are $7.8,3.5$ and $4.5 \%$, respectively.

An average woman of the general Dutch population who starts hormone therapy at age 55 can prolong her life by 1 month where she uses it for 10 years, and 2 months where she continues to use it for 20 years (Table 2). She may postpone the occurrence of first incidence of one of the three diseases in question by 2.4 months where she uses hormone therapy for 10 years, and by 5 months where she continues to use it for 20 years. This postponement is the net effect of a delay in the occurrence of heart attack and hip fracture and an

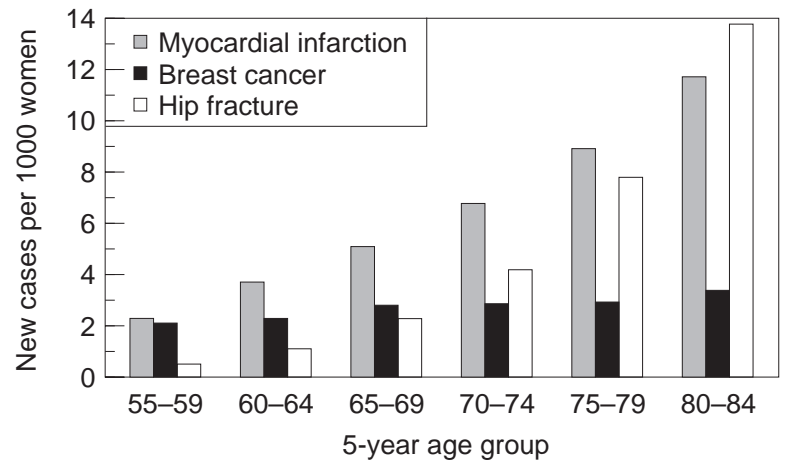

Fig. 1 Age-specific incidence rates for women in the Netherlands.

Table 2 Gain in life expectancy and disease-free period for a 55year-old Dutch woman on hormone therapy during 10 or 20 years according to her cardiovascular risk profile; hormones reduce $\mathrm{CHD}$ risk by $36 \%$

\begin{tabular}{|c|c|c|c|}
\hline Duration of use & No use & 10 years & 20 years \\
\hline \multicolumn{4}{|l|}{ Average risk } \\
\hline Life expectancy (years) & 27.2 & +0.08 & +0.19 \\
\hline Disease-free $^{\mathrm{a}}$ (years) & 23.7 & +0.20 & +0.41 \\
\hline \multicolumn{4}{|l|}{ High-risk } \\
\hline Life expectancy (years) & 25.8 & +0.19 & +0.43 \\
\hline Disease-free $^{\mathrm{a}}$ (years) & 21.6 & +0.46 & +0.90 \\
\hline
\end{tabular}

${ }^{\text {a}}$ Period free of the three diseases under consideration.

acceleration in that of breast cancer. In order to prevent one first heart attack or hip fracture, 83 women must use combined therapy for 10 consecutive years (Table 3). The number is lowered by two-thirds when the use is prolonged to 20 years. One excess breast cancer case is likely to occur per 5-6 averted cases of first myocardial infarction or hip fracture for 10 years of use. The risk-benefit ratio worsens to 3-4 averted cases per extra breast cancer case when the use is prolonged to 20 years.

Table 3 Number-needed-to-treat to prevent one first heart attack or hip fracture and relative number of prevented cases per extra incident of breast cancer (risk-benefit ratio) after 10 and 20 years of hormone therapy according to the cardiovascular risk profile; hormones reduce CHD risk by $36 \%$

\begin{tabular}{lcclll}
\hline & \multicolumn{2}{l}{ Average risk } & & \multicolumn{2}{l}{ High risk } \\
\cline { 2 - 3 } \cline { 5 - 6 } Duration of use & 10 years & 20 years & & 10 years & 20 years \\
\hline Number-needed-to-treat & 83 & 28 & & 38 & 15 \\
Risk-benefit ratio & 5.5 & 3.4 & & 14.8 & 7.0 \\
\hline
\end{tabular}


In cases where a woman has a high-risk profile for cardiovascular disease, her life expectancy is 17 months shorter and her disease-free period is about 2 years shorter (Table 2). In that case, she may prolong her life by well over 2 or 5 months, and her disease-free period by 5.5 or almost 11 months, when use is continued for 10 or 20 years, respectively. Thirty-eight women need to take hormones for a period of 10 consecutive years, or 15 women for a period of 20 years, to prevent one first heart attack or hip fracture (Table 3). The balance between benefit and harm is also more favourable than in the population at large. Yet the risk-benefit ratio also worsens considerably for 20 as compared with 10 years of use.

If the existing estimates for $\mathrm{CHD}$ reduction are overrated and the real reduction is half as large as that assumed by Grady, then the gain in life expectancy and disease-free life expectancy will be halved (Table 4). This holds for both women with an average and those with a high-risk profile for cardiovascular diseases. The number-needed-to treat and the risk-benefit ratio for both risk profiles would then be 1.5-1.7 times less favourable (Table 5). The sensitivity analysis for 20 years of hormone use indicates that the incidence of myocardial infarction determines gains in life expectancy (data not shown). The risk-benefit relation is affected most by changes in the incidence of breast cancer, followed by those of heart attack. Changes in the incidence of hip fracture do not affect life expectancy and hardly affect the risk-benefit relation.

\section{Discussion}

Our data indicate that 10 or 20 consecutive years of

Table 4 Gain in life expectancy and disease-free period for a 55year-old Dutch woman on hormone therapy for 10 or 20 years according to her cardiovascular risk profile; hormones reduce CHD risk by $20 \%$

\begin{tabular}{llll}
\hline Duration of use & No use & 10 years & 20 years \\
\hline Average risk & & & \\
$\quad$ Life expectancy (years) & 27.2 & +0.04 & +0.08 \\
$\quad$ Disease-free (years) & 23.7 & +0.11 & +0.21 \\
High-risk & & & \\
$\quad$ Life expectancy (years) & 25.8 & +0.10 & +0.22 \\
Disease-free $^{\mathrm{a}}$ (years) & 21.6 & +0.26 & +0.49 \\
\hline
\end{tabular}

${ }^{\text {a }}$ Period free of the three diseases under consideration.
Table 5 Number-needed-to-treat to prevent one first heart attack or hip fracture and relative number of prevented cases per extra incident of breast cancer (risk-benefit ratio) after 10 and 20 years of hormone therapy according to the cardiovascular risk profile; hormones reduce CHD risk by $20 \%$

\begin{tabular}{lccccc}
\hline & \multicolumn{2}{c}{ Average risk } & & \multicolumn{2}{l}{ High risk } \\
\cline { 2 - 3 } \cline { 6 - 6 } Duration of use & 10 years & 20 years & & 10 years & 20 years \\
\hline Number-needed-to-treat & 133 & 42 & & 65 & 25 \\
Risk-benefit ratio & 3.4 & 2.3 & & 8.9 & 4.4 \\
\hline
\end{tabular}

hormone therapy would offer only modest gains to the general population of Dutch postmenopausal women. The gains for women with a high cardiovascular risk profile, an estimated one-seventh of the women in the age range 55-64 years, are considerably larger than for the general population. However, the risk-benefit ratio still worsens when the duration of use is prolonged from 10 to 20 years.

The modest gain in life expectancy and diseasefree life expectancy for Dutch women using hormones during 10 or 20 years following menopause results from the low incidence of hip fractures and CHD in relation to the relatively high incidence of breast cancer in the age range 55-75 years. The risk-benefit ratio worsens with the extension of use from 10 to 20 years, irrespective of the cardiovascular risk profile. The worsening of the ratio with longer duration of use, even amongst high-risk women, is a result of the hormone-related excess risk of breast cancer which only becomes fully manifest after long-standing use.

A white American woman can add one extra year to her life when she continues the use of hormones lifelong $[1,7]$ and a British woman can add one extra year to her life when she continues the use for 20 years [6]. In comparison with American and British women, the calculated 2 month gain after 20 years of use for Dutch women is limited. A portion of the noted differences may be ascribed to specific characteristics of the distinctive models. Our assumptions on the size of a hormone-related effect were on the conservative side. We were as modest in our CHD effects as Grady et al. [1] and only Col et al. [7] has assumed a more deleterious effect on breast cancer.

The gain in life expectancy and disease-free period for Dutch women might be smaller if the assumed 
$36 \%$ reduction in CHD is substantially biased. An important source of bias is the healthy user effect: women who use hormones on a long-term basis have a more favourable risk profile for CHD than do non-users [18]. A recent Swedish study that tried to take account of the healthy user bias reported a $25 \%$ reduction in risk of heart attack for long-term hormone therapy with potent oestrogens [19]. Without such a correction, the reduction was $32 \%$. If a $25 \%$ reduction is closer to the true hormone effect, the profits of long-term hormone use will converge to the results presented for the hypothetical 0.8 estimate we used for a bias-free CHD effect.

We did not consider the inclusion of stroke, as we assumed the effect of hormone therapy on stroke rates to be minimal, following Grady et al. [1]. Daly et al. [6], however, assumed hormone therapy to have a beneficial effect on stroke and included stroke in their model. They also assumed a persisting hormone-related effect on heart disease, hip fracture and breast cancer after discontinuation of a 20-year period of use. The latter assumption, in particular, will have contributed substantially to the overall gain in life expectancy, considering the increasing burden of heart disease and hip fracture in older age. So far, empirical data have not shown that, after discontinuation of hormone use, the risk of dying from heart disease remains reduced [20] or that the risk of dying from breast cancer remains elevated [2]. Furthermore, hip fracture risk is not reduced in previous users [21]. We therefore did not assume a persisting hormone effect.

We included only acute myocardial infarction and deaths resulting from those infarctions - acute and in the long run - in our model as measures for CHD, in contrast with the other models. Because other manifestations of $\mathrm{CHD}$ and their consequences for health, such as heart failure, may also be preventable by hormone use, our restriction will underestimate the potential health gain. We applied this restriction because the morbidity data available on the other CHD diagnoses did not allow us to estimate incidence and subsequent survival reliably. About $80 \%$ of the Dutch women who die from ischaemic heart disease between the ages of 55 and 75 die from a heart attack. When we used a slightly different model, which included death from all ischaemic heart disease, the gain of life for Dutch women on hormone therapy was $30 \%$ greater than that shown by the present model (data not shown). Such a gain is still of modest size.

Not all heart attacks are brought to medical attention, and of those that are, not all are recognized as such, in particular in women. Because our model is based on registered events, the figures may underestimate the true heart attack incidence, and thus the potential health gain. We do not know to what extent. The sensitivity analysis showed that if a woman from the general population has a $20 \%$ higher chance of a heart attack than the registered events indicate, she can prolong life by 2.5 instead of 2 months when she uses hormones for 20 years. The corresponding risk-benefit ratio improves to 4 instead of 3-4 averted cases per extra case of breast cancer. The other models against which we compare our results are also based on registered events.

The most likely explanation for the relatively limited gains in prolongation of life experienced by Dutch women in comparison with American and British women is the restriction of use to the early postmenopausal years. In those years, the overall baseline mortality and the baseline morbidity and mortality patterns in heart disease differ considerably between the populations. For example, British [3] and American women [22] between the ages of 55 and 74 are more likely to die from any cause and are also more likely to die from cardiovascular disease, in particular CHD, than are Dutch women of the same age group [3]. The reporting of potential coronary deaths for the purpose of the registration of causes of death varies by country [23]. For a meaningful comparison of the hormone-related outcomes, it is important to know to what extent differences in recorded CHD mortality between populations reflect real differences in coronary events and to what extent they refer to varying coding practices.

The number of 83 Dutch women with an average cardiovascular risk profile who need to use a combined regimen for 10 years in order to prevent a first heart attack or hip fracture conveys the low incidence of the preventable diseases shortly after menopause. So does the corresponding risk-benefit ratio of 5-6 prevented cases per extra breast cancer case. When the use is continued, the numberneeded-to-treat becomes more favourable, but the corresponding risk-benefit ratio becomes worse. The hormone-related effects on morbidity, as opposed to the effects on the prolongation of life, seem to be 
even less advantageous in a population in which cardiovascular disease is much more frequently occurring. Whilst Daly et al. [6] showed that British women can prolong their life substantially by hormone use, they calculated one extra hospitalization for breast cancer per two prevented admissions for ischaemic heart disease or hip fracture between the ages of 50 and 69 years if women were to use a combined regimen for 10 years starting at age 50 . White American women also run a relatively high risk of cardiovascular disease, as indicated by the numbers-needed-to-treat reported by $\mathrm{Col}$ et al. [8]. Although that number becomes more favourable when the use is extended from 10 to 20-30 years, the corresponding risk-benefit ratios for women of average cardiovascular and breast cancer risk remain constant and not very favourable: 3-4 averted cases of CHD or hip fracture per extra case of breast cancer.

Life expectancy is an overall measure in which the contribution of the distinct diseases is not visualized. The not so favourable risk-benefit ratios even for American and British women indicate that in populations of high cardiovascular risk as well, the hormone-related increase in breast cancer risk weighs heavily on the final outcome. This puts the attainable profits of long-term hormone use in another light. It warrants caution against planning a preventive strategy on expected gains in life expectancy alone, without a separate evaluation of the effects on the risk and the benefit side of the balance. Besides, the risk-benefit ratios show the importance of including effects on morbidity, and not just mortality, in weighing the pros and cons of a preventive strategy.

In conclusion, with the existing risk estimates of hormone therapy, our model projects only limited gains for 10 or 20 years of hormone use by Dutch women from the general population. They represent a population of intermediate cardiovascular risk. The gains are larger for women with a high cardiovascular risk profile. However, even amongst the high-risk women, the risk of breast cancer incurred with long-term use offsets much of the benefit that could accrue from changing the risk of heart disease and hip fractures.

\section{Acknowledgements}

We thank Professor A. M. Walker, Professor A.
Hofman and M. A. Rookus for their comments on a draft of this paper.

\section{References}

1 Grady D, Rubin SM, Petitti DB et al. Hormone therapy to prevent disease and prolong life in postmenopausal women. Ann Intern Med 1992; 117: 1016-37.

2 Collaborative Group on Hormonal Factors in Breast Cancer. Breast cancer and hormone replacement therapy: collaborative reanalysis of data of 51 epidemiological studies of 52,705 women with breast cancer and 108,411 women without breast cancer. Lancet 1997; 350: 1047-59.

3 WHO. World Health Statistics Annual. Geneva: World Health Organization, 1998.

4 Hulley S, Grady D, Bush T et al. for the Heart and Estrogen/ progestin Replacement Study (HERS) Research Group. Randomized trial of estrogen plus progestin of secondary prevention of coronary heart disease in postmenopausal women. J Am Med Assoc 1998; 280: 605-13.

5 Gorsky RD, Koplan JP, Perterson HB, Thacker SB. Relative risks and benefits of long-term estrogen replacement therapy: a decision analysis. Obstet Gynecol 1994; 83: 161-66.

6 Daly E, Vessey MP, Barlow D, Gray A, McPherson K, Roche M. Hormone replacement therapy in a risk benefit perspective. Maturitas 1996; 23: 247-59.

7 Col NF, Eckman MH, Karas RH et al. Patient-specific decisions about hormone replacement therapy in postmenopausal women. J Am Med Assoc 1997; 277: 1140-47.

8 Col NF, Pauker SG, Eckman MH, Orr RK, Ross EM, Wong JB. Individualizing therapy to prevent long-term consequences of estrogen deficiency in postmenopausal women. Arch Intern Med 1999; 159: 1458-66.

9 Barendregt JJ, Van Oortmarssen GJ, van Hout BA, Bosch JM, Bonneux L. Coping with multiple morbidity in a life table. Mathematical Population Studies 1998; 7: 29-49.

10, Visser O, Coebergh JWW, Schouten LJ, eds. Incidence of Cancer in the Netherlands, 1989. Utrecht: Netherlands Cancer Registry, 1992.

11 Coebergh JWW, Van der Heijden LH, Janssen-Heijnen MLG. Cancer Incidence and Survival in the Southeast of the Netherlands 1955-1994. Eindhoven: IKZ, 1995.

2 De Laet CE, Van Hout BA, Burger H, Weel HE, Hofman A, Pols HA. Hip fracture prediction in elderly men and women: validation in the Rotterdam Study. J Bone Miner Res 1998; 13: 1587-93.

13 Central Bureau of Statistics. Overledenen naar Doodsoorzaak, Leeftijd en Geslacht (serie a), Primaire Doodsoorzaken 1993, Nederland [in Dutch]. Voorburg: CBS, 1995.

14 Bonneux L, Barendregt JJ, Van der Maas PJ. The new old epidemic of coronary heart disease. Am J Public Health 1999; 98: 379-82.

15 Barentsen R. The climacteric in the Netherlands: a review of Dutch studies on epidemiology, attitudes and use of hormone replacement therapy. Eur J Obstet Gynecol Reprod Biol 1996; 64 (suppl. 1): s7-11.

16 Hofman A, Grobbee DE, De Jong PT, Van den Ouweland FA. Determinants of disease and disability in the elderly: the Rotterdam Elderly Study. Eur J Epidemiol 1991; 7: 403-22.

17 Califf RM, Armstrong PW, Carver JR, D'Agostino RB, Strauss 
WE. Task force 5. Stratification of patients into high, medium and low risk subgroups for purposes of risk factor management. J Am Coll Cardiol 1996; 27: 1007-19.

18 Barrett-Connor E, Grady D. Hormone replacement therapy, heart disease, and other considerations. Аnnu Rev Public Health 1998; 19: 55-72.

19 Grodstein F, Stampfer MJ, Falkeborn M, Naessen T, Persson I. Postmenopausal hormone therapy and risk of cardiovascular disease and hip fracture in a cohort of Swedish women. Epidemiology 1999; 5: 476-80.

20 Grodstein F, Stampfer MJ, Colditz GA et al. Postmenopausal hormone therapy and mortality. N Engl J Med 1997; 336: 1769-75.

21 Cauley JA, Seeley DG, Ensrud K, Ettinger B, Black D, Cummings SR for the Study of Osteoporotic Fractures Research Group. Estrogen replacement therapy and fractures in older women. Ann Intern Med 1995; 122: 9-16.
22 National Vital Statistic System. Unpublished Tabulations on 1995. Hyattsville: National Center for Health Statistics, 1997.

23 Turnstall-Pedoe H, Kuulasmaa K, Amouyel P, Arveiler D, Rakjakangas A-M, Pajak A. Myocardial infarction and coronary deaths in the World Health Organization MONICA project. Registration procedures, events rates and casefatality rates in 38 populations from 21 countries in four continents. Circulation 1994; 90: 583-612.

Received 3 December 1999; revision received 20 March 2000; accepted 18 April 2000.

Correspondence: Clara J. Moerman MD PhD, Department of Gender and Health, RmJ3-320, Academic Medical Centre, University of Amsterdam, Meibergdreef 15, 1105 AZ, Amsterdam, the Netherlands (fax: + 3120 5669143; e-mail: c.j.moerman@amc.uva.nl). 